\title{
Reinserção Social de Psicóticos: Componentes Verbais e Não-Verbais do Comportamento Assertivo, em Situações de Fazer e Receber Críticas
}

\author{
Marina Bandeira ${ }^{12}$ \\ Elaine Leandro Machado \\ Edinéia Aparecida Pereira \\ Universidade Federal de São João Del Rei
}

\section{Resumo}

Foram investigados os componentes verbais e não-verbais da assertividade para lidar com críticas de 35 pacientes psicóticos desinstitucionalizados, comparativamente a 35 sujeitos não-clínicos. Dois observadores treinados observaram os sujeitos interagindo com interlocutores em quatro situações sociais de asserção negativa, de fazer e receber críticas, em desempenho de papéis gravados em vídeo. Variou-se o tipo de situação e o gênero do interlocutor. Os resultados mostraram que a frequência e duração dos componentes verbais e não-verbais da assertividade foram significativamente inferiores no grupo clínico. Observouse uma correlação significativa entre componentes verbais e não-verbais. Os dois grupos foram mais assertivos nas situações de fazer críticas do que nas de receber crítica. Ambos os grupos apresentaram maior assertividade diante do interlocutor masculino, para a maioria dos componentes. Estes resultados replicam dados de outros pesquisadores, indicando a necessidade do treinamento de assertividade em programas de reinserção social, em nosso contexto.

Palavras-chave: Comportamento assertivo; psicóticos; reinserção social; desinstitucionalização; desempenho de papéis.

Social Integration of Psychotics: Verbal and Non-verbal Components of Assertive Behavior in Interpersonal Situations of Making and Receiving Criticism

\section{Abstract}

This research investigated the verbal and non-verbal components of assertive behavior in situations of dealing with criticism of 35 psychotics compared to 35 non-clinical subjects. Two trained judges observed them interacting with trained partners in four negative assertion role-play situations, regarding giving anda receiving criticism, which were videotaped. Types of situations and gender of partners were varied. Results showed a significant deficit of verbal and non-verbal components of assertive behavior in the clinical group. Verbal and non-verbal components correlated significantly. Both groups were more assertive in the situations they were required to criticize their partners compared to situations where they have been criticized. Both groups were more assertive when interacting with male partner, for most of the componentes. These results in general replicated data from others researchers and indicates that brasilian psychiatric patients need to receive assertive training for implementing their social integration.

Keywords: Assertive behavior; psychotics; social integration; desinstitutionalization; role play.

A reinserção social dos pacientes psiquiátricos requer um conjunto de intervenções coordenadas em diversas dimensões da vida dos pacientes, paralelamente ao tratamento medicamentoso, tais como programas de acompanhamento e de readaptação psicossocial, necessários ao bom funcionamento social destes pacientes na comunidade. Um dos componentes destes programas, que é freqüentemente utilizado, consiste no treinamento das habilidades sociais e das habilidades instrumentais básicas, necessárias à sua vida cotidiana (Bandeira, Cardoso, Fernandes, Resende \& Santos, 1998; Bandeira

Endereço para correspondência: Departamento de Psicologia - FUNREI, Praça Dom Helvécio, 74, São João del Rei, MG, 36.300-000. E-mail: bandeira@funrei.b

${ }^{2}$ Esta pesquisa foi realizada com financiamento da FAPEMIG e do CNPq. Agradecemos ao Prof. João Domingos Scalon pela consultoria para análise estatística dos dados.
\& Tremblay, 1998). Estes treinamentos se tornaram necessários na reinserção social dos pacientes, devido ao déficit destas habilidades em seu repertório (Bellack, Morrison, Mueser, Wade \& Sayer, 1990; Brown \& Carmichael, 1992). Diversas revisões de pesquisas nesta área têm demonstrado que o treinamento das habilidades sociais produz um impacto positivo no funcionamento social dos pacientes e em sua reinserção social, diminuindo suas taxas de reospitalizações (Bellack, Turner, Hersen \& Kazdin, 1986; Hogarty e cols., 1991; Mueser, Wallace \& Liberman, 1995).

Uma das subcategorias das habilidades sociais consiste no comportamento assertivo, que é definido como a capacidade do indivíduo de se afirmar em interações sociais, defendendo seus direitos, expressando suas opiniões, idéias, necessidades e insatisfações e solicitando mudanças de comportamento das outras pessoas, sem 
desrespeitar os direitos dos outros. O comportamento assertivo envolve igualmente aspectos não-verbais, tais como falar num tom de voz claro e audível, olhar o interlocutor durante a conversa sem desviar demais o olhar, falar o tempo necessário para expor completamente sua opinião, responder prontamente ao interlocutor etc. (Caballo, 1996; Del Prette \& Del Prette, 1999; Gambril, 1978 Lange \& Jakubowski, 1976). O comportamento assertivo inclui habilidades de lidar com situações sociais negativas, como por exemplo, recusar um pedido abusivo, e positivas, tais como agradecer ou fazer um elogio (Eisler, Hersen, Miller \& Blanchard, 1975; Mueser, Bellack, Morrison \& Wade, 1990; Rathus, 1975)

O comportamento assertivo é necessário em uma grande diversidade de situações sociais, sendo porém, particularmente importante naquelas situações cotidianas que envolvem conflitos interpessoais e que podem resultar em estresse para os pacientes psiquiátricos, uma vez que eles geralmente não dispõem de habilidades de enfrentamento para atuar satisfatoriamente nestas situações, o que constitui um fator de risco para recidivas destes pacientes (Cyr, Hodgins, Gaston \& Viens, 1990; Zubin \& Spring, 1977). Tendo em vista a vulnerabilidade particular dos pacientes psicóticos a situações estressantes (Zubin \& Spring, 1977) e seu déficit de habilidades sociais e de comportamento assertivo (Bellack, Morrison, Mueser, Wade \& Sayer, 1990), torna-se mais difícil o enfrentamento destas situações interpessoais problemáticas que ocorrem no dia-a-dia. Segundo Bellack, Morrison e Mueser (1989), a dificuldade de lidar de maneira eficaz com o ambiente social é considerada como uma fonte importante de estresse que contribui para a recidiva dos pacientes. $\mathrm{O}$ treinamento do comportamento assertivo serve para desenvolver a capacidade de enfrentamento e resolução de problemas interpessoais atuando, portanto, como um fator de proteção para os pacientes e visando promover uma melhora no funcionamento social e na qualidade de vida destas pessoas.

Devido à vulnerabilidade destes pacientes a estímulos sociais estressantes, torna-se particularmente pertinente estudar, de forma mais detalhada, seu comportamento em situações de asserção negativa. De fato, estas foram as situações enfatizadas no estudo de Cyr e colaboradores (1990) e no levantamento feito por Tremblay (1992) sobre as principais dificuldades sociais de pacientes psiquiátricos desinstitucionalizados. Dentre as situações levantadas por Tremblay (1992), aquelas que mais discriminaram o grupo clínico do grupo não-clínico foram as situações de recebe e fazer crítica, que serão utilizadas no presente trabalho.

O estudo do comportamento assertivo requer a identificação cuidadosa dos componentes específicos verbais e não-verbais indicativos de assertividade, que servirão para operacionalizar este conceito, além de possuir pertinência clínica, uma vez que indicadores específicos são necessários e mais pertinentes no contexto de um treinamento de assertividade. Uma maneira de se identificar estes componentes específicos é a partir da observação sistemática do comportamento dos sujeitos em interações sociais, através de desempenho de papéis, o que tem sido amplamente utilizado nesta área de estudo (Bellack e cols., 1990; Eisler e cols., 1975; Mueser e cols., 1990). Este tipo de avaliação requer uma metodologia que se baseie em procedimentos rigorosos de coleta de dados, que são necessários para se obter medidas válidas e fidedignas, a partir dos dados coletados pelos observadores (Bellack, 1983). Além disso, como o comportamento assertivo e as habilidades sociais, em geral, possuem uma especificidade situacional, pois se trata de desempenho e não de traço (Caballo, 1996; Del Prette \& Del Prette, 1999; Gambrill, 1978), sua avaliação deve ser feita em diferentes tipos de situações, por exemplo, variando-se o tipo de demanda da situação e/ou o tipo de interlocutor. No presente trabalho será utilizada a metodologia de observação sistemática e as variações de demanda da situação e de gênero do interlocutor.

Tendo em vista a importância do comportamento assertivo para o funcionamento social e para o sucesso da reinserção social dos pacientes psiquiátricos, além disso, considerando a dificuldade particular destes pacientes em situações sociais negativas, o presente trabalho teve como objetivo fazer uma análise observacional do desempenho de pacientes psiquiátricos em situações de asserção negativa, referentes a fazer e receber crítica, buscando verificar as dificuldades de assertividade apresentadas por estes pacientes, comparativamente a um grupo de referência de sua comunidade. Pesquisas anteriores demonstraram as dificuldades apresentadas por pacientes psiquiátricos com relação a diversos componentes das habilidades sociais (Bandeira e cols., 1998; Bandeira \& Tremblay, 1998). O presente trabalho se concentrou em uma das categorias das habilidades sociais, que é o comportamento assertivo, buscando identificar quais são as dificuldades específicas dos pacientes, em termos de freqüência e duração dos componentes verbais e nãoverbais indicadores da assertividade, em situações de fazer e receber críticas.

\section{Método}

\section{Participantes}

Foi avaliada uma amostra de 70 indivíduos do sexo masculino, de nível socio-econômico baixo, habitantes de 
uma mesma região geográfica, composta por dois grupos, clínico e não-clínico. O grupo clínico consistia de 35 pacientes psiquiátricos desinstitucionalizados, diagnosticados como psicóticos (CID 295 e 298), com idade média de 39,4 anos. O grupo de referência era composto por 35 indivíduos com idade média de 37,4 anos, que não apresentavam história psiquiátrica. Foi utilizada a mesma amostra de participantes de uma pesquisa anterior (Bandeira \& Tremblay, 1998), tendo em vista que seus desempenhos sociais haviam sido gravados anteriormente, permitindo assim a realização de novos estudos.

A equivalência dos dois grupos com relação às variáveis sócio-demográficas foi investigada, constatando-se que eles eram equivalentes quanto à idade, estado civil, renda familiar e percapita, tipo de residência e número de repetições escolares (Bandeira \& Tremblay, 1998). Esta equivalência dos grupos possibilita uma maior validade interna da pesquisa e uma maior confiabilidade dos resultados.

\section{Instrumento de Medida}

O comportamento assertivo foi avaliado através da observação dos participantes em desempenho de papéis efetuado em quatro situações de interação social com interlocutores previamente treinados para este fim. Esta observação foi realizada por dois observadores treinados para observar e cotar exclusivamente os componentes verbais e não-verbais da assertividade, a partir da visualização de interações gravadas em vídeo. Estes dois observadores trabalharam independentemente um do outro.

Os interlocutores haviam sido previamente treinados para interagir com os sujeitos, através de réplicas múltiplas padronizadas, porém flexíveis o suficiente para se adaptarem às falas do sujeito (Bellack, 1983), permitindo assim um diálogo mais natural e pertinente (Bandeira \& cols., 1998; Bandeira \& Tremblay, 1998). As situações sociais utilizadas neste trabalho foram retiradas de uma escala canadense adaptada para o Brasil e representam exemplos cotidianos de situações de asserção negativa, referentes a fazer e receber crítica, que requerem um comportamento assertivo dos sujeitos frente a interlocutores do sexo masculino e feminino (Bandeira e Tremblay, 1998). Situações Sociais

Os participantes foram observados em situações sociais que representavam conflitos interpessoais entre membros de uma família e que requeriam um desempenho assertivo. Foram utilizadas quatro situações sociais negativas, divididas em dois tipos: duas situações de receber crítica e duas situações de fazer crítica. Para cada tipo de situação, alternou-se o gênero do interlocutor, ou seja, uma situação envolvia um interlocutor do sexo masculino e a outra envolvia um interlocutor do sexo feminino. No primeiro tipo de situação social, o sujeito deveria expressar sentimentos negativos de insatisfação com o Psicologia: Reflexão e Crítica, 2002, 15(1), pp. 89-104 comportamento do interlocutor e pedir a mudança do seu comportamento. No segundo tipo de situação, o sujeito deveria reagir a uma crítica justificada feita pelo interlocutor, defendendo seu ponto de vista, expressando a sua necessidade específica na situação e propondo uma solução para o problema que satisfizesse suas necessidades, sem desrespeitar a do outro.

Medidas de Assertividade

Para avaliar a assertividade dos sujeitos nas quatro situações, foram utilizadas medidas de freqüência e duração, assim como medidas de grau de adequação dos componentes verbais e não-verbais, que são empregadas nos principais estudos de assertividade e de habilidades sociais de pacientes psiquiátricos (Bellack, 1983; Bellack e cols., 1990; Eisler e cols., 1975, Millbrook \& Farrell, 1986; Mueser e cols., 1990), os quais se baseiam principalmente no trabalho de Wolpe (1969), Lazarus (1971) e Rathus (1975). No caso da dimensão verbal, foram utilizadas também duas hierarquias de comportamentos envolvendo maior ou menor grau de assertividade e de submissão, elaboradas a partir dos resultados de pesquisas anteriores (Bandeira, Pereira \& Machado, 1999). Abaixo, são definidas as medidas verbais e não-verbais utilizadas na presente pesquisa.

Medidas de Assertividade Verbal

A assertividade verbal dos participantes foi avaliada, em cada situação, através de três medidas de componentes verbais: 1 . Uma medida do comportamento verbal de expressar necessidade ou insatisfação frente ao problema apresentado na situação social; 2. Uma medida do comportamento verbal de propor uma solução que satisfizesse a ambas as partes ou pedir uma mudança de comportamento do interlocutor 3. Uma medida derivada do Conteúdo Verbal Global, que envolvia a soma dos dois primeiros componentes. No caso da medida de expressar verbalmente uma insatisfação, o comportamento era computado mesmo quando o sujeito expressava apenas os fatos referentes ao comportamento indesejável do interlocutor, sem necessariamente expressar verbalmente os sentimentos de forma explícita. Esta definição foi adotada, em função dos resultados obtidos por Bandeira e colaboradores (1998), a partir dos quais ficou evidente que a falta de expressão dos sentimentos é uma realidade presente em ambos os grupos de sujeitos clínicos ou nãoclínicos, provavelmente característica da subcultura na qual estão inseridos e, portanto, deveria ser excluída como critério de avaliação do desempenho dos pacientes.

O Conteúdo Verbal Global é uma medida derivada a partir da soma das duas primeiras medidas definidas acima. Esta medida era calculada da seguinte maneira: cada comportamento verbal valia um ponto quando era 
emitido pelo sujeito, ou valia zero, caso não fosse emitido. Como havia dois componentes verbais para cada situação, obtínhamos um máximo de dois pontos para cada situação e um total de 8 pontos no máximo para as quatro situações. Esta medida de Conteúdo Verbal variava, portanto, de zero a dois em cada situação e de zero a oito no total das quatro situações.

Foram utilizadas também duas medidas adicionais para avaliar o desempenho global de assertividade e de submissão dos sujeitos, que envolviam uma combinação de todos os comportamentos verbais possíveis na situação, ordenados em itens graduais, sob forma de uma hierarquia. As duas hierarquias utilizadas estão definidas abaixo.

Hierarquia de assertividade: Esta hierarquia foi elaborada a partir do repertório de comportamentos apresentados pelos sujeitos no estudo de Bandeira e colaboradores (1999), no qual foram utilizadas as mesmas situações do presente trabalho. Para construir esta hierarquia, foram estabelecidas todas as combinações possíveis de presença e ausência dos comportamentos verbais assertivos nas situações, em ordem crescente, num total de 13 combinações. Atribuía-se aos sujeitos uma pontuação que podia variar de um a 13 pontos, descritos a seguir: Ponto 1: era o nível mais baixo desta hierarquia e representava o comportamento de não falar nad durante toda a situação, mantendo-se calado em resposta às falas do interlocutor. Ponto 2: era atribuído ao sujeito que respondia às falas do interlocutor apenas com monossílabos. Ponto 3: eqüivalia ao comportamento de responder verbalmente às falas do interlocutor, porém sem expressar sua necessidade ou insatisfação, nem propor uma solução para a situação. Ponto 4: era atribuído ao sujeito que respondia ao interlocutor, mas não expressava sua necessidade ou insatisfação, e propunha uma solução que considerava apenas a necessidade do outro. Ponto 5: referia-se ao sujeito que não expressava sua necessidade ou insatisfação e propunha uma solução que considerava apenas a sua própria necessidade. Ponto 6: o sujeito expressava sua necessidade ou insatisfação, mas voltava atrás antes que o interlocutor pedisse uma solução. Ele não propunha solução para a situação. Ponto 7: era atribuído ao sujeito que expressava sua necessidade ou insatisfação, mas não propunha solução para o problema que estava sendo discutido com o interlocutor, aceitando a solução proposta pelo interlocutor. Ponto 8 referia-se àquele sujeito que expressava sua necessidade ou insatisfação, propunha uma solução assertiva, ma voltava atrás com relação à sua proposta. Ponto 9: valor atribuído ao sujeito que expressava sua necessidade ou insatisfação, mas propunha uma solução que não tinh relação com a situação e que não resolvia a questão apresentada pelo interlocutor. Ponto 10: eqüivalia ao sujeito que expressava necessidade ou insatisfação e propunha uma solução que não satisfazia a sua própria necessidade, levando em consideração apenas as necessidades do outro. Ponto 11: o sujeito que recebia esta pontuação era aquele que expressava sua necessidade ou insatisfação e propunha uma solução que só satisfazia suas próprias necessidades, sem levar em conta as necessidades do outro. Ponto 12: era atribuído ao sujeito que propunha uma solução, sem no entanto ter expressado sua necessidade ou insatisfação. $\mathrm{Na}$ sua fala, ele abordava diretamente a solução assertiva. Ponto 13: era o nível mais alto da hierarquia e correspondia ao sujeito que expressava claramente sua necessidade ou insatisfação, propondo uma solução assertiva que satisfazia suas necessidades, sem desrespeitar as necessidades do interlocutor.

Hierarquia de submissão: Esta hierarquia foi igualmente construída a partir do repertório de comportamentos apresentados pelos sujeitos no estudo de Bandeira e colaboradores (1999). Para construir esta hierarquia, foram selecionadas quatro possíveis combinações de presença e ausência de comportamentos submissos, em ordem decrescente de submissão. O observador avaliava a submissão do sujeito frente ao interlocutor através de uma pontuação de 1 a 4 pontos, descritos a seguir: Ponto 1: nível mais baixo da hierarquia indicando maior grau de submissão, no qual o sujeito se submetia totalmente ao interlocutor sem reagir, sem expressar suas necessidade, sem defender seus direitos. Ponto 2: o sujeito falava de seus direitos, mas se submetia ao interlocutor no final. Ponto 3 : valor atribuído ao sujeito que falava de seus direitos e, além disso, argumentava defendendo suas necessidades, mas se submetia no final. Ponto 4: correspondia ao nível mais alto da hierarquia e indicava menor grau de submissão, no qual o sujeito não se submetia e nem se impunha ao interlocutor, expressando e argumentando sobre sua necessidade, sem desconsiderar a necessidade do outro.

\section{Medidas de Assertividade Não-Verbal}

Dois tipos de medida foram usadas na avaliação dos comportamentos não-verbais envolvidos na assertividade: 1. As medidas de duração e freqüência de comportamentos e 2. As medidas de classificação através de uma escala de tipo Likert de cinco pontos, que avaliavam o grau de adequação de alguns comportamentos não-verbais.

As medidas de duração e freqüência dos comportamentos implicados na assertividade foram as seguintes: 1. Duração da fala: tempo total durante o qual o sujeito falou com o interlocutor, iniciando-se a partir da sua primeira fala após a introdução do assunto específico da situação, excluindose cumprimentos, agradecimentos e despedidas. 2.Duração da situação: tempo total do diálogo entre o sujeito e o 
interlocutor, a partir do momento em que o problema da situação era introduzido pelo interlocutor até o momento em que o interlocutor encerrava a situação, excluindo-se o tempo dispendido com cumprimentos e despedidas. 3.Proporção de duração da fala: medida derivada que consistia no tempo de duração da fala do sujeito dividido pelo tempo total de duração da situação. 4 . Duração do contato visual: soma total dos intervalos de tempo em que o sujeito olhou em direção ao rosto do interlocutor. Cada contato visual foi medido a partir do momento em que o sujeito virava a cabeça em direção aos olhos do interlocutor até o momento em que ele desviava o olhar. 5.Proporção do contato visual: medida derivada que consistia no tempo de duração do contato visual do sujeito dividido pelo tempo de duração da situação. 6. Duração das latências: soma total dos intervalos de tempo decorridos entre o término de cada fala do interlocutor e o início da fala do sujeito. Não foi considerada a latência do sujeito após a última fala do interlocutor que encerra cada situação. 7. Duração dos silêncios: soma total dos intervalos de tempo em que o sujeito permanecia calado em resposta às falas do interlocutor. Cada intervalo de silêncio do sujeito era contado a partir do final de uma fala do interlocutor até a sua fala seguinte. 8. Alterações da fala: número de distúrbios da fala apresentados pelo sujeito, tais como gagueira, pausas de mais de três segundos, repetições de frases ou de palavras e expressões não-funcionais entre as frases, tais como $A$, ehn, uhn etc. 9. Proporção das alterações da fala: medida derivada que consistia no número de alterações da fala do sujeito dividido pelo tempo total em que este falou durante a situação. 10. Freqüência dos silêncios: número de vezes em que o sujeito permanecia calado após as falas do interlocutor, portanto não respondendo às suas intervenções.

As medidas referentes à duração dos componentes não-verbais eram calculadas após cada observador tomar três medidas repetidas de cada comportamento específico. O observador considerava então o valor mediano destas três medidas que ele havia tomado. Este procedimento foi adotado devido ao fato de se tratar de medidas muito específicas, que envolviam a cronometragem de segundos e centésimos de segundos, o que dificultava a tarefa dos observadores. O procedimento adotado serviu para aumentar a precisão destas medidas.

As medidas de classificação, que avaliaram a adequação de componentes não-verbais relacionados à assertividade, através de uma escala tipo Likert de 5 pontos, foram as seguintes: Volume da vor: Grau de intensidade da voz, medido através da seguinte escala: 1 . Muito baixo: tom de voz muito inaudível, impossível de ser ouvido; 2.
Baixo: parcialmente inaudível, ouvia-se algumas palavras; 3. Médio: a fala era audível na maioria das vezes, mas precisando melhorar para ser satisfatório, no limite; 4. Alto: tom de voz audível, podia-se ouvir bem as falas do sujeito, satisfatório; 5. Muito alto: o tom de voz era completamente audível, suficientemente alto, ideal. Afeto apropriado: o sujeito deveria veicular emoção ao interagir com o interlocutor e esta emoção deveria ser congruente com a situação. Este componente era medido a partir da seguinte escala: 1. Muito inapropriado: expressão de afeto muito incongruente com a situação, totalmente inaceitável, por exemplo, risos; 2. Inapropriado: incongruente com a situação, inaceitável; 3. Médio: expressão de sentimentos que chegava a ser congruente com a situação, mas precisava melhorar; 4. Apropriado: afeto congruente com a situação, sendo satisfatório; 5 . Muito apropriado: o sentimento veiculado estava totalmente congruente com a situação, ideal, o desempenho se destacava dos demais. Entonação da voz: modulação do tom de voz que dá ênfase ao conteúdo da fala, avaliado segundo a seguinte escala: 1 Muito inexpressiva: sem nenhuma ênfase ou modulação; 2. Inexpressiva: em geral sem ênfase; 3 . Média: chegava a ter ênfase, mas precisava melhorar para ser aceitável; 4. Expressiva: o tom de voz tinha ênfase, sendo satisfatório; 5. Muito expressiva: com ênfase acentuada, ideal, se destacando dos demais.

\section{Procedimento}

Os dois observadores foram treinados durante três meses, até atingirem $85 \%$ de acordo em suas avaliações. Após o treinamento, procedeu-se à coleta dos dados propriamente dita, que durou aproximadamente quatro meses. Para isto, fossem feitas a observação e a cotação dos comportamentos verbais e não-verbais dos 70 sujeitos da pesquisa nas quatro situações sociais, totalizando 280 cenas de interação social.

Observação e Cotação dos Comportamentos

Os juizes estavam "cegos" com relação aos grupos, ou seja, eles observaram e cotaram o desempenho dos sujeitos, sem saber a qual grupo eles pertenciam, a fim de evitar erros sistemáticos de observação. Além disso, os sujeitos foram observados em uma ordem aleatória, as gravações de um e outro grupo tendo se alternado aleatoriamente. As falas dos sujeitos nas situações haviam sido transcritas e estas transcrições foram utilizadas para orientar o trabalho dos observadores.

A coleta de dados era feita diariamente, tendo cada sessão de observação uma duração de três horas. Cada juiz observava por um hora e em seguida fazia-se a reunião de consenso entre eles, descrita abaixo. Era cotado o comportamento apenas de um sujeito por dia, a fim de 
evitar que o cansaço interferisse na qualidade das observações. Os juizes observavam e contavam independentemente um do outro.

Em cada dia de observação, os juizes observavam as quatro situações de um dado sujeito, começando pela primeira situação até a quarta, nesta ordem. Para cada situação, cotava-se primeiro todos os comportamentos não-verbais, e em seguida, os comportamentos verbais do sujeito observado naquele dia. Cada componente do comportamento não-verbal era observado e cotado separadamente, seguindo-se a ordem em que estes componentes estavam listados na Folha de Registro de Comportamentos. Portanto, a fita era rebobinada diversas vezes para que os juizes observassem apenas um componente de cada vez, podendo assim concentrar melhor sua atenção em um dado componente. Em seguida passava-se à observação dos componentes verbais do mesmo sujeito, na mesma situação, utilizando-se o mesmo procedimento descrito acima. Os dados obtidos por cada juiz eram anotados separadamente em uma folha de registro de comportamentos. Estes eram os dados utilizados posteriormente para o cálculo de acordos inter-juizes.

Terminadas as observações dos dois juízes, iniciava-se a reunião de consenso. Neste momento, era computado o número de medidas coincidentes dos dois observadores o número de desacordos. No caso das medidas de freqüência e das medidas de classificação em escala tipo Likert, er considerado como acordo duas medidas idênticas. No caso das medidas de duração de comportamentos, como estas durações eram quase sempre de segundos e centésimos de segundos, estabeleceu-se uma margem de acordo. Assim, foram consideradas como duas medidas concordantes entre os dois observadores, aquelas cuja diferença era menor do que dez por cento. Os dados obtidos separadamente por cada um dos juizes, antes do estabelecimento do consenso, eram utilizados para se calcular a porcentagem de acordos obtida entre eles, naquele dia. Estes eram os dados usados igualmente para se calcular as correlações entre juizes no final da pesquisa

Após calcular a porcentagem de acordos obtidos, os juizes discutiam os desacordos encontrados entre eles até chegar a um consenso. No caso das medidas de duração de um comportamento, este consenso era obtido calculando-se a média das medidas obtidas pelos dois juizes. No caso das medidas em escala tipo Likert de cinco pontos, o consenso consistia em um acordo obtido pelos juízes, após uma discussão a respeito dos critérios que haviam utilizado e a partir das definições dos comportamentos dispostos em uma Grade de Definições. Os dados obtidos a partir deste consenso foram então utilizados na análise estatística dos resultados.
Fidedignidade das Medidas

A fidedignidade das medidas utilizadas foi avaliada através de dois tipos de procedimento: o cálculo do acordo inter-observadores e o cálculo do acordo intra-observador.

Acordo inter-observadores: $\mathrm{O}$ acordo entre os juízes foi avaliado através de dois métodos. Em ambos os casos, para se fazer este cálculo, foram utilizados os dados que haviam sido obtidos separadamente por cada juiz, antes do estabelecimento das medidas consensuais. O primeiro método consistiu no cálculo da porcentagem diária de acordo obtido entre os observadores para o conjunto de todas as medidas nas quatro situações. Os resultados mostraram que houve uma média de $94 \%$ de acordo entre os dois observadores em suas cotações diárias. $\mathrm{O}$ segundo método de cálculo do acordo inter-observadores consistiu na análise de correlação de Spearman entre as cotações dos juizes para cada componente da assertividade. Para se fazer esta análise, foi sorteada uma amostra de $30 \%$ dos sujeitos da pesquisa, ou seja, 21 sujeitos. Foram calculados os coeficientes de correlação de Spearman entre os escores dados separadamente pelos dois juizes a esta amostra de 21 sujeitos.

Os resultados mostraram um alto grau de acordo entre os juízes para os componentes não-verbais de adequação do afeto $(r=1,00 ; p=0,00)$, alterações da fala $(r=$ $1,00 ; p=0,00)$, volume da voz $(r=1,00 ; p=0,00)$, freqüência e duração dos silêncios $(r=1,00 ; p=0,00)$, entonação da voz $(r=0,99 ; p=0,00)$, duração do contato visual $(r=0,99 ; p=0,00)$, duração da fala $(r=0,98$; $p=0,00)$ e latência da fala $(r=0,96 ; p=0,00)$. O grau de acordo foi também elevado para os componentes verbais de propor uma solução $(r=0,98 ; p=0,00)$, expressar necessidade ou insatisfação $(r=0,96 ; p=0,00)$ e conteúdo verbal total $(r=0,95 ; p=0,00)$.

Estes resultados mostraram que os dois juízes estavam observando e medindo de forma muito semelhante, o que indica portanto, uma boa fidedignidade das medidas observacionais obtidas no presente trabalho. Estes altos escores de fidedignidade podem ser atribuídos a diversos fatores, tais como: o prolongado treinamento ao qual os juizes foram submetidos, o uso de critérios específicos e bem definidos de avaliação, o fato de se observar apenas um componente de cada vez, o fato de se observar apenas um sujeito por dia e a utilização de grades de registro de resposta com definições específicas dos comportamentos a serem observados. Além disso, para algumas medidas, cada juiz observava três vezes um mesmo componente e considerava a mediana destas três medidas como o seu escore final, o que diminuiu muito o número de desacordos. Finalmente, um procedimento que contribuiu, provavelmente, para aumentar o acordo 
entre os juízes foi o fato de se calcular todos os dias a porcentagem de acordo obtido entre eles, de forma que eles recebessem um feedback diário do seu desempenho.

Acordo intra-observador: Foi avaliado igualmente, no final da pesquisa, o grau de acordo intra-observador obtido por cada um dos dois observadores. Para isto, cada observador repetiu a observação de algumas categorias de comportamentos dos mesmos sujeitos após um intervalo de três semanas. $\mathrm{O}$ acordo intra-observador foi avaliado através do cálculo das correlações entre os escores obtidos para os comportamentos dos mesmos sujeitos nestes dois momentos. As categorias submetidas ao acordo intra-observador foram: hierarquia de assertividade, hierarquia de submissão, freqüência de silêncio e duração do silêncio.

$\mathrm{O}$ acordo intra-juizes foi calculado através da correlação de Spearman para um subgrupo de 30\% dos sujeitos da pesquisa. Os resultados mostraram que o coeficientes de correlação foram altamente significativos para todos os componentes de comportamento observados, tanto para o juiz 1 quanto para o juiz 2. Os coeficientes de correlação obtidos para o juiz 1 foram os seguintes: hierarquia de assertividade $(r=0,96 ; p=0,00)$, hierarquia de submissão $(r=0,93 ; p=0,00)$, freqüência de silêncio $(r=0,99 ; p=0,00)$ e duração do silêncio $(r=$ $0,99 ; p=0,00)$. Para o juiz 2 , os coeficientes de correlação obtidos foram: hierarquia de assertividade $(r=0,99 ; \mathrm{p}=$ $0,00)$, hierarquia de submissão $(r=0,96 ; p=0,00)$, freqüência de silêncio $(r=1,00 ; p=0,00)$ e duração do silêncio $(r=1,00 ; p=0,00)$.

Os resultados apresentados acima mostram que o acordo obtido intra e inter-juizes foi elevado, o que indica uma alta fidedignidade das medidas utilizadas na presente pesquisa. Os altos escores de fidedignidade obtidos aqui podem ser atribuídos às características do procedimento de coleta de dados de observação adotado na presente pesquisa, que já foram descritos acima.

\section{Resultados}

As contribuições relativas das dimensões verbais e nãoverbais da assertividade para diferenciar os grupos clínico e não-clínico podem ser apreciadas através dos resultados de uma Análise Discriminante englobando os componentes verbais e não-verbais. Esta análise mostrou que a dimensão verbal da assertividade foi a que mais diferenciou os grupos de sujeitos no presente trabalho. A função discriminante englobando os componentes destas duas dimensões foi significativa ( $c 2=37,32 ; d f=10 ; p=0,00$; correlação canônica $=0,68$; eigenvalue $=0,88 ;$ Wilks'Lambda $=0,53$ ).

A ordem de importância dos componentes verbais e não-verbais para diferenciar os dois grupos foi determinada a partir do grau de correlação canônica de Psicologia: Reflexão e Crítica, 2002, 15(1), pp. 89-104 cada um dos componentes com a função criada pela análise discriminante. Assim, observamos que dentre as categorias de comportamento de assertividade estudadas, a que mais diferenciou os grupos foi o conteúdo verbal da fala do sujeito (c.c. $=0,86)$. Em seguida, os demais componentes não-verbais contribuíram para diferenciar os grupos, na seguinte ordem decrescente: entonação da $\operatorname{voz}($ c.c. $=0,46)$, adequação do afeto c.c. $=0,44)$, proporção da duração da fala $(c . c .=0,35)$; freqüência de silêncios (c.c. $=-0,33)$, duração do silêncio (c.c. $=-0,32)$. Os demais componentes não-verbais apresentaram correlações abaixo de 0,30 com a função discriminante, portanto, tiveram uma menor importância na discriminação dos grupos.

Apresentaremos abaixo os resultados obtidos na avaliação da assertividade verbal, da assertividade nãoverbal e, em seguida, as relações observadas entre as dimensões verbais e não-verbais. Dentro de cada uma destas categorias, serão apresentados separadamente os resultados que se referem primeiro às diferenças encontradas entre os dois grupos e, em seguida, às diferenças observadas na maneira de cada grupo reagir a diferentes tipos de situações.

\section{Assertividade Verbal}

Os dados referentes à assertividade verbal foram analisados em termos do Conteúdo Verbal Global e em termos de seus dois componentes específicos. As Tabelas 1 a 4 apresentam os resultados da assertividade verbal dos grupos clínico e não-clínico nas quatro situações, no que se refere à estes dois tipos de medidas. Os dados foram analisados em termos das diferenças observadas entre os grupos e em termos das diferentes maneiras de reagir de cada grupo frente aos tipos de situações estudadas. Abaixo apresentaremos separadamente cada uma destas categorias de resultados.

Uma primeira análise dos dados por Manova de medidas repetidas mostrou que há um efeito significativo de grupo, ou seja, os dois grupos se diferenciaram no total das quatro situações $(F=28,18 ; p=0,00)$. Verificouse igualmente, que há um efeito significativo de situações, demonstrando que os grupos reagiram diferentemente em função das mudanças introduzidas de uma situação para a outra $(F=85,45 ; p=0,00)$.

Diferenca entre os grupos: As Tabelas 1 e 2 apresentam os resultados referentes às médias e desvios-padrão do Conteúdo Verbal Global e dos seus dois componentes específicos da assertividade verbal. Para investigar a diferença entre os grupos com relação a estas variáveis, em cada situação separadamente e no conjunto das situações, fez-se uma análise estatística através de Anova. 
Na Tabela 1 temos os dados relativos ao Conteúdo Verbal Global, ou seja, a medida derivada que consistia na soma das duas habilidades verbais observadas (expressar necessidade e propor uma solução para o problema discutido).

Podemos observar que os participantes do grupo clínico apresentaram um Conteúdo Verbal Global assertivo significativamente inferior ao do seu grupo de comportamento do interlocutor ou propor solução ( $F$ $=17,17 ; p=0,00)$ do que seu grupo de referência.

Diferenças de reação aos tipos de situação: Para verificar como os sujeitos reagiram às duas diferentes situações (fazer e receber crítica), foram analisadas as reações de cada grupo de sujeitos separadamente, utilizando-se o teste $t$ de Student.

A Tabela 3 mostra os resultados referentes ao Conteúdo Verbal Global e aos seus componentes específicos em função

Tabela 1. Médias e Desvios-Padrão do "Conteúdo Verbal Global de Assertividade" Apresentado pelos Grupos Clínico e Não-Clínico nas Quatro Situações e Média Global

\begin{tabular}{|c|c|c|c|c|c|}
\hline $\begin{array}{l}\text { Grupo/ } \\
\text { Situação }\end{array}$ & 1 & 2 & 3 & 4 & Média Global \\
\hline Clínico & $0,17(0,39)$ & $1,29(0,63)$ & $0,62(0,70)$ & $1,35(0,81)$ & $3,34(1,78)$ \\
\hline Não-Clínico & $0,54(0,61) * *$ & $1,94(0,23) * * *$ & $1,14(0,60) * * *$ & $1,66(0,48) *$ & $5,29(1,13) * * *$ \\
\hline
\end{tabular}

referência, no conjunto das quatro situações $(F=29,74$; $p=0,00)$. Ao analisar os dados de cada situação separadamente, constatamos igualmente que estes resultados se confirmam, pois os pacientes apresentaram um Conteúdo Verbal Global significativamente inferio ao do seu grupo de referência, em cada situação particular: situação $1(F=9,30 ; p=0,003)$, situação $2(F=32,54 ; \mathrm{p}=$ $0,000)$, situação $3(F=12,22 ; p=0,001)$ e situação $4(F=$ $4,45 ; p=0,039)$.

Resultados semelhantes foram observados ao se analisar cada componente verbal separadamente. A Tabela 2 apresenta os dados relativos aos dois componentes verbais de assertividade: 1. expressar necessidade ou insatisfação e 2. propor solução ou pedir mudança de comportamento.

Os resultados mostram que os pacientes apresentaram uma freqüência significativamente menor do comportamento de expressar sua insatisfação ou necessidade do que o seu grupo de referência $(F=19,08 ; p=0,00)$. Eles apresentaram também uma freqüência significativamente menor do comportamento de pedir mudança do do tipo de situação, para cada grupo de sujeitos. Podemos observar que, no que se refere ao Conteúdo Verbal Global, tanto o grupo clínico $(t=-10,03 ; p=0,00)$ quanto o grupo não-clínico $(t=-9,87 ; p=0,00)$ foram mais assertivos ao fazerem crítica do que ao receberem crítica. Esta mesma diferença se observa também ao se analisar separadamente os componentes específicos da assertividade verbal. O grupo de pacientes $(t=-6,94 ; p=0,00)$ e seu grupo de referência $(t=-6,35 ; p=0,00)$ apresentaram uma freqüência maior do comportamento de expressar insatisfação ao interlocutor ao fazerem crítica do que ao receberem crítica. Do mesmo modo, os grupos clínico $(t=-6,02 ; p=0,00)$ e não-clínico $(t=-8,35 ; p=0,00)$ propunham mais solução ao interlocutor ao fazerem crítica do que ao receberem crítica.

Diferenças de reação frente ao gênero do interlocutor: As Tabelas 4 e 5 apresentam os dados referentes às reações dos dois grupos em relação ao gênero do interlocutor. A Tabela 4 mostra as diferenças observadas nas reações dos sujeitos em função desta variável, no que se refere ao Conteúdo

Tabela 2. Médias e Desvios-Padrão dos Componentes Verbais de Assertividade "Expressar Necessidade/ Insatisfação" e "Propor Solução/Pedir Mudança de Comportamento" Apresentados pelos Grupos Clínico e Não-Clínico nas Quatro Situações

\begin{tabular}{lcc}
\hline Grupos & $\begin{array}{c}\text { Expressar necessidade/ } \\
\text { Insatisfação }\end{array}$ & $\begin{array}{c}\text { Propor solução/pedir mudança } \\
\text { de comportamento }\end{array}$ \\
\hline Clínico & $2,32(0,94)$ & $1,12(1,04)$ \\
Não-Clínico & $3,23(0,77)^{* * *}$ & $2,06(0,84) * * *$ \\
\hline
\end{tabular}

$* p<0,05 \quad * * p<0,01 \quad * * * p<0,001$ 
Tabela 3. Médias e Desvios-Padrão do "Conteúdo Verbal Assertivo" e dos Dois Componentes Específicos da Assertividade Verbal (Expressar Necessidade/Insatisfação e Propor Solução/Pedir Mudança de Comportamento) Apresentados pelos Grupos Clínico e Não-Clínico, em Função do Tipo de Situação

\begin{tabular}{lllllll}
\hline Componentes & \multicolumn{2}{c}{$\begin{array}{c}\text { Conteúdo } \\
\text { Verbal Assertivo }\end{array}$} & \multicolumn{2}{c}{$\begin{array}{c}\text { Expressar } \\
\text { Necessidade/Insatisfação }\end{array}$} & \multicolumn{2}{c}{$\begin{array}{c}\text { Propor Solução/Pedir } \\
\text { Mudança de Comportamento }\end{array}$} \\
\hline Tipos de situação & Receber & Criticar & Receber & Criticar & Receber & Criticar \\
Clínico & $0,79(0,77)$ & $2,65(1,20)^{* * *}$ & $1,06(0,49)$ & $1,71(0,58)^{* * *}$ & $0,18(0,39)$ & $0,94(0,81)^{* * *}$ \\
Não-Clínico & $1,69(0,99)$ & $3,60(0,55)^{* * *}$ & $1,46(0,50)$ & $2,00(0,00)^{* * *}$ & $0,46(0,61)$ & $1,60(0,55)^{* * *}$ \\
\hline$* p<0,05 * * * p<0,01$ & $* * * p<0,001$ & & & &
\end{tabular}

Verbal Global assertivo e aos seus dois componentes específicos.

Podemos observar na Tabela 4 que os sujeitos do grupo clínico $(t=-2,08 ; p=0,05)$ e também os do grupo não-clínico $(t=-5,62 ; p=0,00)$ foram mais assertivos verbalmente ao interagirem com um interlocutor masculino do que com um interlocutor feminino, no que se refere à medida do Conteúdo Verbal Global.

Esta mesma diferença se observa também para o primeiro componente da assertividade verbal, que é o de expressar necessidade ou insatisfação. Quando se combina estes dois comportamentos, podemos observar (Tabela 4) que os sujeitos do grupo clínico $(t=-3,45 ; p=$ $0,002)$, assim como os do grupo não-clínico $(t=-3,51 ; p=$ $0,001)$, foram mais assertivos face ao interlocutor do gênero masculino.

Entretanto, ao separar estes dois comportamentos, observamos (Tabela 5) que os grupos só foram mais assertivos face ao interlocutor masculino no que se refere ao comportamento de expressar uma necessidade e não no que se refere ao comportamento de expressar insatisfação.

A Tabela 5 mostra que o grupo clínico $(t=-2,95 ; p$ $=0,006)$ e o grupo não-clínico $(t=-3,51 ; p=0,001)$ expressaram sua necessidade mais freqüentemente ao interlocutor masculino. Porém, os dois grupos não variaram ao expressar insatisfação.

Por outro lado, os resultados referentes ao segundo componente da assertividade verbal (propor solução ou pedir mudança de comportamento) variaram de um grupo para o outro. No caso deste componente, o grupo clínico não apresentou nenhuma variação significativa $(t=0,529$; $p=0,600)$, enquanto que o grupo não-clínico apresentou uma reação diferenciada em função do gênero do interlocutor $(t=-4,346 ; p=0,00)$. De fato, o grupo não-clínico (Tabela 5) pediu mais mudança de comportamento ( $t=3,26$; $p=$ $0,003)$ e também propôs mais solução para o problema discutido $(t=-3,26 ; p=0,003)$ ao interagir com um interlocutor masculino, do que com um interlocutor feminino.

Podemos constatar portanto que, no que se refere ao segundo componente verbal, o grupo de pacientes apresentou uma menor variabilidade de comportamento assertivo em função do gênero do interlocutor.

Correlação entre as Medidas de Assertividade Verbal: Para verificar o grau de concordância entre a medida de Conteúdo Verbal Global e as demais medidas de assertividade verbal dos sujeitos, foi feita uma análise correlacional de Spearman entre os escores desta medida e os escores das medidas de hierarquia de assertividade

Tabela 4. Médias e Desvios-Padrão do "Conteúdo Verbal Assertivo" e dos Dois Componentes Específicos da Assertividade Verbal (Expressar Necessidade/Insatisfação e Propor Solução/Pedir Mudança de Comportamento) Apresentados pelos Grupos Clínico e Não-Clínico, em Função do Gênero do Interlocutor

\begin{tabular}{|c|c|c|c|c|c|c|}
\hline \multirow{2}{*}{$\begin{array}{l}\text { Componentes } \\
\text { Gênero Interlocutor }\end{array}$} & \multicolumn{2}{|c|}{$\begin{array}{c}\text { Conteúdo Verbal } \\
\text { Assertivo }\end{array}$} & \multicolumn{2}{|c|}{$\begin{array}{c}\text { Expressar Necessidade/ } \\
\text { Insatisfação }\end{array}$} & \multicolumn{2}{|c|}{$\begin{array}{c}\text { Propor Solução/Pedir } \\
\text { Mudança de } \\
\text { Comportamento }\end{array}$} \\
\hline & Feminino & Masculino & Feminino & Masculino & Feminino & Masculino \\
\hline Clínico & $1,53(0,93)$ & $1,91(1,08)^{*}$ & $0,94(0,55)$ & $1,38(0,65)^{* *}$ & $0,59(0,56)$ & $0,53(0,66)$ \\
\hline Não-Clínico & $2,20(0,80)$ & $3,09(0,66)^{* * *}$ & $1,46(0,50)$ & $1,77(0,43)^{* * *}$ & $0,74(0,61)$ & $1,31(0,53)^{* * *}$ \\
\hline
\end{tabular}


Tabela 5. Médias e Desvios-Padrão dos Componentes "Expressar Necessidade" (Sit. 1 e 3 ) "Expressar Insatisfação" (Sit. 2 e 4) e "Propor Solução" (Sit. 1 e 3), "Pedir Mudança de Comportamento" (Sit. 2 e 4) em Função do Gênero, Apresentados pelos Grupos Clínico e Não-Clínico

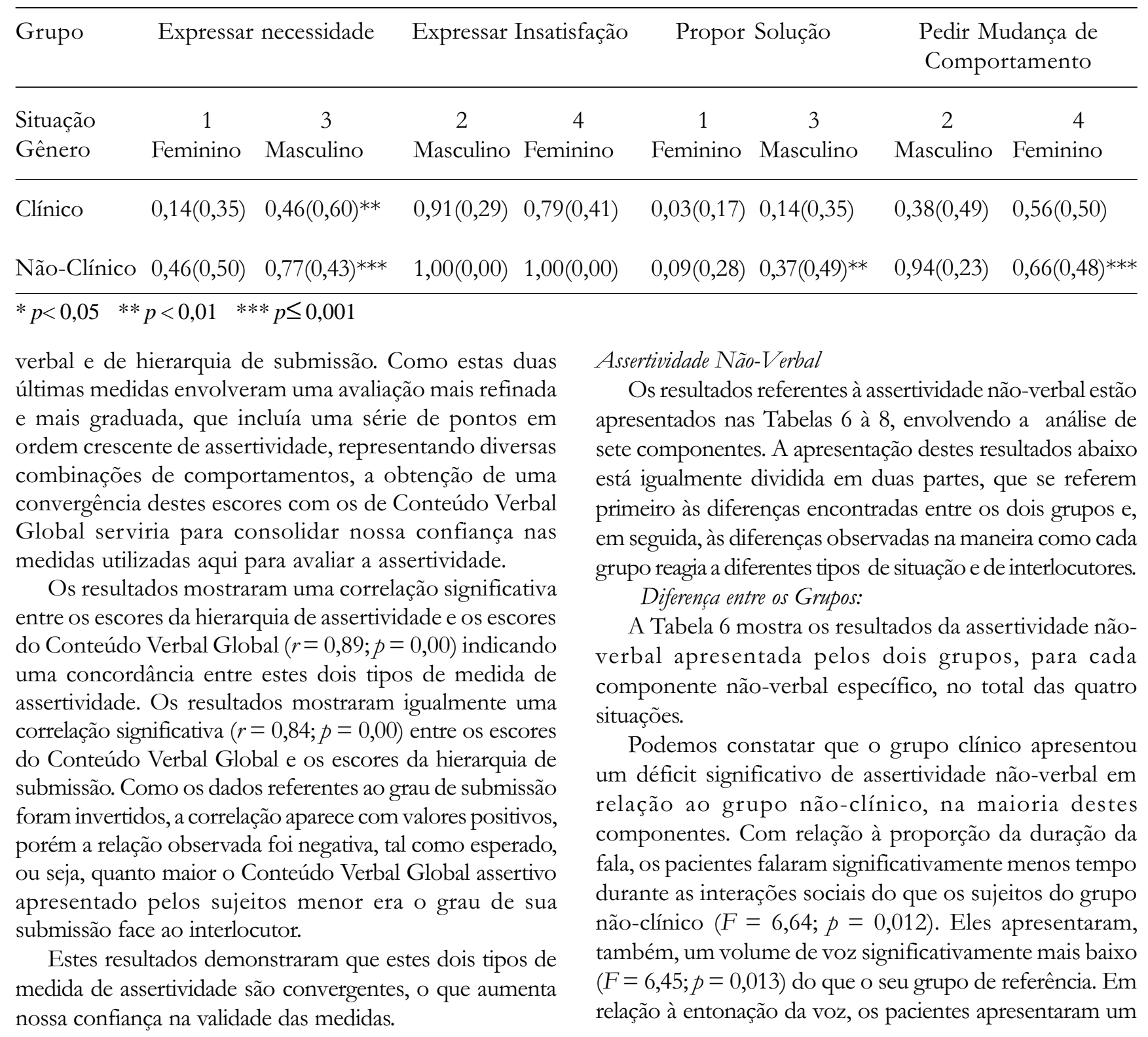

Tabela 6. Médias e Desvios-Padrão dos Componentes da Assertividade Não-Verbal Apresentados pelos Grupos Clínico e Não-Clínico

\begin{tabular}{|c|c|c|c|c|c|c|c|c|c|}
\hline Grupo & $\begin{array}{l}\text { Entonação } \\
\text { da Voz }\end{array}$ & Afeto & $\begin{array}{c}\text { Proporção } \\
\text { da Fala }\end{array}$ & $\begin{array}{c}\text { Volume da } \\
\text { Voz }\end{array}$ & $\begin{array}{l}\text { Proporção } \\
\text { Alterações } \\
\text { da Fala }\end{array}$ & Latência & $\begin{array}{l}\text { Proporção } \\
\text { Contato } \\
\text { Visual }\end{array}$ & $\begin{array}{l}\text { Freqüência } \\
\text { Silêncios }\end{array}$ & $\begin{array}{l}\text { Duração } \\
\text { Silêncios }\end{array}$ \\
\hline Clínico & $2,78(0,79)$ & $2,97(0,73)$ & $27,40(15,55)$ & $3,39(0,98)$ & $0,08(0,06)$ & $1,47(0,78)$ & $0,65(0,24)$ & $1,26(2,32)$ & $6,39(1.07)$ \\
\hline $\begin{array}{l}\text { Não- } \\
\text { Clínico }\end{array}$ & $3,38(0,61) * * *$ & $3,47(0,47)^{\text {*** }}$ & $37,01(15,64) *$ & $3,89(0,63) *$ & $0,05(0,05)$ & $1,32(0,59)$ & $0,55(0,24)$ & $0,34(1,30)^{* 1}$ & $1,83(0,73)^{*}$ \\
\hline
\end{tabular}


tom de voz significativamente menos modulado e menos expressivo $(F=12,94 ; p=0,001)$. Além disso, os pacientes apresentaram um déficit significativo com relação à adequação do afeto veiculado na interação social, comparativamente ao seu grupo de referência $(F=11,77 ; p$ $=0,001)$. Finalmente, podemos observar que os pacientes emitiram maior freqüência de silêncios em resposta às falas do interlocutor do que seu grupo de referência $(F=4,13 ; p$ $=0,05)$ e a duração dos períodos de silêncio apresentados por eles foi maior $(F=4,32 ; p=0,04)$ do que a do seu grupo de referência.

Com relação aos demais componentes da assertividade não-verbal, o grupo clínico não apresentou uma diferença significativa em relação ao seu grupo de referência, no que se refere às seguintes variáveis: proporção de alterações da fala $(F=2,93 ; p=0,091)$, contato visual $(F=2,94 ; p=$ $0,091)$ e latência da resposta $(F=0,81 ; p=0,37)$.

Diferenças de reação aos tipos de situação: As Tabelas 7 e 8 mostram os resultados referentes à assertividade nãoverbal dos sujeitos em função do tipo de situação social. Com relação ao tipo de situação, a Tabela 7 apresenta os dados apenas do grupo clínico.

Podemos observar que os sujeitos deste grupo apresentaram maior assertividade não-verbal nas situações de fazer crítica do que nas situações de receber crítica, para alguns componentes. Assim, eles apresentaram uma menor latência da fala $(t=3,79 ; p=0,001)$, uma maior proporção da duração da fala $(t=-6,11 ; p=0,00)$ e uma entonação de voz mais apropriada $(t=-2,31 ; p=0,027)$ nas situações de fazer crítica. Quanto ao contato visual, observamos que os pacientes olharam menos tempo o interlocutor nestas situações $(t=4,27 ; p=0,00)$. Este resultado é teoricamente esperado e se explica pelo fato do sujeito estar falando mais e ouvindo menos neste tipo de situação e, neste caso, o contato visual é previsivelmente menos prolongado, ao contrário de uma situação de maior escuta, onde o contato visual deve ser mais prolongado.

Coerentemente com os resultados apresentados acima, o grupo clínico apresentou também uma freqüência $(t=$ $2,68 ; p=0,01)$ e uma duração do silêncio $(t=2,14 ; p=$ $0,04)$ significativamente menores nas situações de fazer crítica, o que indica portanto maior assertividade nãoverbal neste tipo de situação. Com relação aos demais componentes não-verbais, que são o volume da voz, a proporção de alterações da fala e o afeto apropriado, o grupo clínico não apresentou variações significativas em função dos diferentes tipos de situação. Ainda com relação ao tipo de situação, a Tabela 8 apresenta as variações observadas no grupo não-clínico em reação às mudanças efetuadas no tipo de situação.

Podemos constatar os mesmos resultados descritos acima, que foram apresentados anteriormente para o grupo clínico, indicativos de maior assertividade nãoverbal ao fazer crítica do que ao receber crítica. Assim, nas situações de fazer crítica, o grupo de referência também apresentou uma menor latência da fala $(t=2,81 ; p=0,008)$, uma maior proporção da fala $(t=-10,79 ; p=0,00)$ e uma entonação de voz mais assertiva $(t=-2,26 ; p=0,03)$. Quanto à proporção da duração do contato visual, o grupo de referência também olhou menos o interlocutor $(t=2,77$; $p=0,01)$ ao fazer crítica, o que é previsível uma vez que ele fala mais tempo, pois estas duas variáveis tendem a ser inversamente relacionadas. Entretanto, o grupo nãoclínico não apresentou resultados semelhantes ao grupo clínico no que se refere à freqüência e duração dos silêncios. Para este comportamento, embora o grupo nãoclínico tenha apresentado menor duração de silêncios nas situações de fazer crítica do que nas de receber crítica,

Tabela 7. Médias e Desvios-Padrão dos Componentes da Assertividade Não-Verbal Apresentados pelo Grupo Clínico em Função dos Diferentes Tipos de Situação e Gênero do Interlocutor

\begin{tabular}{lrccc}
\hline Componentes Não-Verbais & \multicolumn{2}{c}{ Tipo de Situação } & \multicolumn{2}{c}{ Gênero do Interlocutor } \\
& Receber Crítica & Fazer Crítica & Feminino & Masculino \\
\hline Proporção da fala & $22,43(14,59)$ & $32,69(17,90)^{* * *}$ & $26,24(16,25)$ & $28,30(16,61)$ \\
Entonação da voz & $2,71(0,82)$ & $2,84(0,80)^{*}$ & $2,74(0,81)$ & $2,81(0,80)$ \\
Latência da fala & $3,69(2,44)$ & $2,28(1,19)^{* * *}$ & $1,42(0,87)$ & $1,22(, 054)$ \\
Proporção de alterações da fala & $0,13(0,15)$ & $0,19(0,20)$ & $0,14(0,14)$ & $0,18(0,16)$ \\
Volume da voz & $3,37(0,96)$ & $3,40(1,06)$ & $3,37(0,99)$ & $3,40(1,02)$ \\
Afeto & $2,94(0,86)$ & $3,00(0,73)$ & $3,04(0,73)$ & $2,88(0,79)^{*}$ \\
Proporção do Contato visual & $0,73(0,30)$ & $0,57(0,23)^{* * *}$ & $0,59(0,27)$ & $0,51(0,23)^{* *}$ \\
Freqüência de silêncios & $0,86(1,46)$ & $0,40(1,04)^{* *}$ & $0,74(1,31)$ & $0,51(1,07)^{*}$ \\
Duração dos silêncios & $4,09(5,97)$ & $2,30(5,82)^{*}$ & $3,49(5,13)$ & $2,90(6,42)$ \\
\hline
\end{tabular}

$* p<0,05 \quad * * p<0,01 \quad * * * p<0,001$ 
100 Marina Bandeira, Elaine Leandro Machado \& Edinéia Aparecida Pereira

Tabela 8. Médias e Desvios-Padrão dos Componentes da Assertividade Não-Verbal Apresentados pelo Grupo NãoClínico em Função dos Diferentes Tipos de Situações e Gênero do Interlocutor

\begin{tabular}{lrccc}
\hline Componentes não-verbais & \multicolumn{2}{c}{ Tipo de situação } & \multicolumn{2}{c}{ Gênero do Interlocutor } \\
& Receber crítica & \multicolumn{1}{c}{ Fazer crítica } & Feminino & Masculino \\
\hline Proporção da fala & $30,23(14,24)$ & $43,79(17,73)^{* * *}$ & $33,63(15,37)$ & $40,39(16,71)^{* * *}$ \\
Entonação da voz & $3,33(0,62)$ & $3,44(0,63)^{*}$ & $3,36(0,67)$ & $3,40(0,63)$ \\
Latência da fala & $3,00(1,38)$ & $2,28(1,43)^{* *}$ & $1,53(0,82)$ & $1,41(0,84)$ \\
Proporção de alterações da fala & $0,10(0,09)$ & $0,12(0,19)$ & $0,11(0,11)$ & $0,11(0,11)$ \\
Volume da voz & $3,93(0,63)$ & $3,84(0,68)$ & $3,94(0,67)$ & $3,83(0,64)$ \\
Afeto & $3,38(0,63)$ & $3,56(0,54)$ & $3,47(0,48)$ & $3,47(0,53)$ \\
Freqüência dos silêncios & $0,17(0,75)$ & $0,17(0,62)$ & $0,20(0,90)$ & $0,14(0,55)$ \\
Duração dos silêncios & $0,98(4,07)$ & $0,85(3,28)$ & $1,14(4,69)$ & $0,69(2,72)$ \\
Proporção do contato visual & $0,73(0,30)$ & $0,57(0,23)^{* * *}$ & $0,65(0,28)$ & $0,55(0,24)^{* * *}$ \\
\hline
\end{tabular}

$* p<0,05 \quad * * p<0,01 \quad * * * p<0,001$

não observamos, entretanto, uma diferença estatisticamente significativa entre estas duas situações. A freqüência dos silêncios não variou para o grupo não-clínico.

Quanto aos componentes volume da voz, proporção de alterações da fala e afeto apropriado, não observamos no grupo não-clínico variações significativas em função dos diferentes tipos de situação, tal como havia sido observado para o grupo clínico.

Diferenças de reação ao gênero do interlocutor: Quanto ao gênero do interlocutor, a Tabela 7 apresenta os dados referentes ao grupo clínico. Podemos observar que os pacientes apresentaram uma maior freqüência de silêncios $(t=2,26 ; \quad p=0,03)$, uma duração maior do contato visual $(t=3,03 ; p=0,005)$ e um afeto mais apropriado $(t=2,34 ; p=0,026)$ frente ao interlocutor feminino. Não há diferença significativa quanto aos outros componentes não-verbais: proporção da duração da fala, volume entonação da voz, latência e proporção de alterações da fala e duração dos silêncios. Os resultados acima, embora não sejam conclusivos devido ao número reduzido de componentes com diferenças significativas, sugerem, entretanto uma tendência de maior assertividade face ao interlocutor masculino.

A Tabela 8 apresenta as reações observadas no grupo não-clínico em função do gênero do interlocutor. Esses sujeitos, tal como aqueles do grupo clínico, olharam também mais tempo para o interlocutor feminino $(t=$ $3,24 ; p=0,003)$. Além disso, o grupo de referência falou mais tempo com o interlocutor masculino $(t=-5,54 ; p=$ $0,00)$. Estes resultados são coerentes, uma vez que o tempo de fala e do olhar tendem a ser inversamente relacionados. Estes resultados indicam maior assertividade não-verbal face ao interlocutor masculino. Não houve variações significativas nos outros componentes não-verbais: afeto, volume e entonação da voz, latência e proporção de alterações da fala, freqüência e duração do silêncios.

Estes resultados mostraram que ambos os grupos variaram menos sua assertividade não-verbal em função do gênero do interlocutor do que em função do tipo de situação.

\section{Relação entre Assertividade Verbal e Não Verbal}

Para verificar as relações existentes entre a assertividade verbal dos sujeitos e os componentes não-verbais foi feita uma análise de Correlação de Spearman entre os escores destes dois dados. Foi observada uma correlação significativa entre os componentes verbais e não-verbais da assertividade. Os resultados indicaram que quanto maior a assertividade verbal apresentada pelo sujeito, mais modulada era a entonação da sua voz $(r=0,54 ; p=0,00)$, menor era o tempo em que ele permanecia em silêncio $(r=-0,49 ; p=0,00)$, menor era a freqüência de ocorrência de silêncios em resposta à fala do interlocutor $(r=-0,49 ; p=$ $0,00)$, maior era a duração da sua fala proporcionalmente à duração da interação social $(r=0,45 ; p=0,00)$, menor era a latência da fala do sujeito $(r=0,44 ; p=0,00)$, maior era o volume de sua voz $(r=0,40 ; p=0,001)$ e mais adequado o afeto que ele veiculava durante a interação social $(r=0,38$; $p=0,001)$.

Portanto, podemos concluir que a assertividade verbal estava relacionada diretamente com maior rapidez ao responder às falas do interlocutor, maior tempo de fala, expressão de sentimentos mais coerentes com a situação vivenciada, tom de voz mais expressivo e modulado, volume da voz mais audível e menor freqüência e duração de períodos de silêncios do sujeito no decorrer da interação social. Os demais componentes não-verbais, que são a proporção de contato visual e a proporção de alterações da fala, apresentaram uma correlação não 
significativa, embora na direção esperada, ou seja, inversamente proporcional ao conteúdo verbal.

\section{Discussão}

Os resultados obtidos nesta pesquisa constataram que o grupo clínico apresentou um déficit nos componentes verbais e não-verbais indicadores da assertividade em relação ao seu grupo de referência na comunidade, em situações de asserção negativa de fazer e receber crítica, com interlocutores masculinos e femininos. Considerando o conceito de assertividade, previamente definido neste trabalho, podemos concluir que os pacientes apresentaram dificuldades na afirmação dos próprios direitos e na expressão honesta de suas opiniões, idéias e necessidades ao interlocutor, nestas situações de asserção negativa.

Os resultados mostraram ainda que o aspecto verbal da assertividade foi o mais deficitário no grupo clínico em relação ao seu grupo de referência, ou seja, este foi o aspecto do déficit de assertividade que mais diferenciou os dois grupos. Constatamos que os pacientes possuíam um déficit verbal não apenas com relação à medida global de assertividade verbal, mas também no que se refere especificamente aos dois componentes verbais estudados. Portanto, observamos uma dificuldade específica em expressar insatisfação ou necessidade ao interlocutor e também uma dificuldade em pedir mudança no comportamento do interlocutor ou propor uma solução para o problema da situação. Além disso, o déficit de assertividade verbal do grupo clínico em relação ao grupo de referência ocorreu independentemente do tipo de situação ou do gênero do interlocutor.

Trower (1980) encontrou resultados semelhantes aos obtidos na presente pesquisa, pois também em seu estudo a dimensão verbal foi a que mais diferenciou o seu grupo de pacientes competentes de um outro socialmente incompetente. Esses resultados confirmaram também os dados obtidos por Tremblay (1992), nos quais a maior dificuldade dos pacientes psiquiátricos em relação ao seu grupo de referência na comunidade estava na dimensão verbal. O déficit dos componentes verbais está presente em outros estudos como um indicador de dificuldades de assertividade. Há uma convergência de dados empíricos obtidos por diversos autores, confirmando o déficit de assertividade verbal dos pacientes psiquiátricos (Bellack e cols.,1990; Morrison \& Bellack,1987; Mueser, Bellack, Douglas \& Morrison, 1991; Mueser e cols., 1990). Além disso, o componente verbal diferencia claramente os pacientes mais assertivos dos menos assertivos, como no estudo de Eisler e colaboradores (1975), onde foi observado que os inassertivos apresentaram menor Psicologia: Reflexão e Crítica, 2002, 15(1), pp. 89-104 freqüência do comportamento verbal de pedir mudanças no comportamento do seu interlocutor, em situações de asserção negativa. Estes resultados concordam também com os obtidos em estudos realizados com sujeitos nãoclínicos, nos quais as pessoas assertivas apresentaram maior freqüência da resposta verbal de pedir mudança de comportamento do interlocutor (Lipp, Haythornwaite \& Anderson, 1996).

Tendo em vista que os nossos resultados, obtidos no contexto brasileiro, confirmam os dados de outros pesquisadores em diferentes contextos culturais, podemos concluir que a dificuldade de ser assertivo e, em particular, a dificuldade de expressão verbal assertiva, caracteriza este tipo de clientela em relação a um grupo não-clínico, independentemente do contexto cultural (Mueser e cols., 1991). Esta observação pode servir, portanto, como parâmetro para a elaboração dos objetivos do treinamento das habilidades sociais, em particular a assertividade, dentro dos programas de reabilitação psiquiátrica, que visam melhorar o funcionamento social do paciente em sua reinserção na comunidade. Um melhor desempenho assertivo dos pacientes contribuiria para uma maior capacidade de enfrentamento de situações de conflito interpessoal, o que resultaria em menor nível de estresse, aumentando consequentemente a qualidade de vida das pessoas.

No que se refere ao tipo de situação, tanto o grupo de pacientes quanto o grupo de referência apresentaram mais dificuldades em serem assertivos verbalmente quando tinham que receber uma crítica do interlocutor e reagir a esta crítica, do que em situações nas quais eles necessitavam fazer uma crítica aocomportamento indesejável do interlocutor. Estes resultados são semelhantes aos dados obtidos por Tremblay (1992), nos quais o seu grupo clínico também apresentou maior dificuldade de se comportar de forma competente nas situações em que recebia uma crítica do interlocutor. Estes resultados sugerem que as situações de receber críticas deveriam ser abordadas mais tardiamente nos treinamentos de assertividade, uma vez que se apresentam com maior grau de dificuldade para os pacientes. Esta questão coloca em destaque a necessidade de se construir uma hierarquia de situações sociais em função de seu grau de dificuldade, para serem usadas nos treinamentos de assertividade $\mathrm{e}$ de competência social, conforme já mencionado por Bellack e colaboradores (1990). Pesquisas futuras poderão investigar outras dimensões a serem consideradas nesta hierarquia.

Quanto ao gênero do interlocutor, podemos concluir que o conteúdo verbal global dos sujeitos de ambos os grupos foi mais assertivo quando eles estavam interagindo 
com interlocutor do sexo masculino. Esta diferença se manteve no que se refere ao componente verbal de expressar necessidade. Por outro lado, ao analisarmos cada grupo separadamente, foi possível constatar que os dois grupos diferiram com relação à sua reação frente aos interlocutores do sexo masculino e feminino, para o segundo componente verbal. Assim, o grupo não-clínico pedia mais mudança de comportamento e propunha mais solução ao interagir com um interlocutor masculino, sendo que os pacientes não apresentaram variações significativas deste componente verbal em função do gênero do interlocutor. Deste modo, constatamos que o grupo clínico apresenta uma menor variabilidade de comportamento em função do gênero do interlocutor.

Estes últimos resultados diferem dos encontrados na literatura da área. Em geral, os resultados a respeito do tipo de interlocutor (gênero e familiaridade) não tem sido homogêneos nos diversos estudos. Por exemplo, Eisler e colaboradores (1975) não observaram diferenças na assertividade verbal de seus sujeitos frente a interlocutores familiares e não familiares. Por outro lado, no que se refere ao gênero dos interlocutores, estes mesmos autores não apresentaram resultados sobre as diferenças de assertividade verbal dos sujeitos inassertivos e não assertivos separadamente, nas situações específicas de interação negativa, mas somente em relação à soma das situações de asserção negativa e positiva. Porém, ao apresentarem os resultados globais do grupo total (assertivos e não-assertivos), seus dados mostram que os sujeitos foram mais assertivos frente ao interlocuto do sexo feminino, contrariamente aos nossos resultados. As divergências observadas entre nossos resultados e o dados obtidos por Eisler e colaboradores (1975) podem resultar talvez das diferenças encontradas entre os dois estudos quanto a forma de analisar os dados, pois no estudo de Eisler e colaboradores (1975) foram analisados os dados do grupo total, no conjunto de situaçõe positivas e negativas. Uma outra hipótese se refere a diferenças culturais entre as duas amostras estudadas. É possível que o comportamento de fazer críticas a um interlocutor do sexo feminino e de pedir mudanças de seu comportamento possuam conotações diferentes para sujeitos masculinos das duas culturas em questão. Novas pesquisas serão necessárias para elucidar a questão das diferenças de assertividade dos sujeitos diante de interlocutores do sexo masculino e feminino.

Comparando-se a variabilidade dos sujeitos em função do tipo de situação e em função do gênero do interlocutor, foi possível constatar que ambos os grupos variaram menos na habilidade de ser assertivos frente a mudanças no gênero do interlocutor do que ao enfrentarem diferentes tipos de situação. Esta menor variabilidade do comportamento dos sujeitos face ao gênero do interlocutor, talvez se explique pelo fato de que as mudanças referentes ao gênero possam ter sido menos contrastantes do que as mudanças relacionadas aos tipos de situação (criticar versus receber uma crítica). É possível, portanto, que os sujeitos tenham reagido de maneira mais diferenciada diante das variações experimentais que eram mais contrastantes. Provavelmente, as situações de criticar e de receber críticas configurem situações negativas de interação social que requeiram um esforço maior de adaptação dos sujeitos para responder adequadamente do que mudanças no gênero do interlocutor.

Não só a assertividade verbal foi mais deficitária no grupo dos pacientes, mas também a assertividade nãoverbal. Dentre os componentes não-verbais estudados, os que mais se destacaram como deficitários no grupo clínico foram a entonação da voz, seguida pelo afeto, proporção da fala e volume da voz. Ou seja, os pacientes falavam menos tempo, de forma mais monocórdia, sem expressividade emocional, e seu volume de voz era mais baixo do que o das pessoas do grupo de referência na comunidade. Além disso, dois outros componentes nãoverbais diferenciaram significativamente os grupos clínico e não-clínico, que foram a freqüência e a duração dos silêncios em resposta ao interlocutor, os quais se mostraram mais acentuados entre os pacientes do que em seu grupo de referência. Estes são dois indicadores de falta de assertividade observados igualmente na pesquisa de Tremblay (1992), na qual os pacientes psiquiátricos estudados apresentaram maior freqüência e duração de silêncios em resposta às falas do interlocutor do que o seu grupo de referência.

Os resultados obtidos aqui com relação aos componentes não-verbais confirmaram ainda os dados de Eisler e colaboradores (1975), segundo os quais os sujeitos inassertivos falavam com um volume de voz mais baixo, com menos expressividade na voz e expressavam um afeto menos adequado com a situação do que os sujeitos assertivos, além de apresentarem maior duração dos silêncios. Trower (1980) mostrou resultados semelhantes a estes, pois em seu estudo os pacientes socialmente incompetentes falavam menos tempo do que os pacientes socialmente competentes. No estudo de Bellack e colaboradores (1990) foi observado igualmente que os sujeitos esquizofrênicos apresentavam menor duração da fala e veiculavam afeto menos apropriado às situações em que estavam envolvidos do que o grupo não-clínico.

Quanto à duração do contato visual, resta a ser feita uma análise sistemática deste componente separadamente na fase de escuta e na fase de elocução dos sujeitos nas 
situações sociais, o que constituirá objeto de pesquisas futuras. Uma tal análise apresentou resultados importantes nas pesquisas de Trower (1980). Foi obtida, por exemplo, uma diferença significativa entre os grupos de sujeitos assertivos e inassertivos, em termos da inversão que se observa geralmente entre a duração da fala e a duração do olhar. Devido à dificuldade deste tipo de observação, ela constituirá objeto de uma pesquisa específica para isto.

Os resultados obtidos aqui nos permitiram também observar que a assertividade não-verbal variou em função do tipo de situação e do gênero do interlocutor. Os resultados mostraram que tanto os pacientes quanto o seu grupo de referência apresentavam maior assertividade não-verbal nas situações de fazer crítica do que nas situações de receber crítica, para os componentes de duração da fala, latência, entonação da voz. Ou seja, eles falavam mais tempo, respondiam mais prontamente e apresentam uma entonação de voz mais assertiva ao fazer uma crítica, o que sugere que este tipo de situação seria mais fácil para ambos os grupos. Além disso, no caso particular dos pacientes, a freqüência e duração dos silêncios também foi menor nas situações de fazer crítica, indicando maior assertividade. Quanto ao gênero do interlocutor, os resultados mostraram que o grupo de referência apresentou maior assertividade não-verbal frente ao interlocutor masculino. Os resultados dos pacientes foram menos consistentes, embora sugestivos de uma conclusão nesta mesma direção.

Alguns componentes não-verbais, tais como volume da voz, alterações da fala e expressão de afeto, não apresentaram diferenças significativas em relação aos tipos de situação ou ao gênero do interlocutor no presente trabalho, contrariamente ao que seria esperado em função do caráter situacional das habilidades sociais (Caballo, 1996; Del Prette \& Del Prette, 1999; Gambrill, 1978). Ao contrário, Eisler e colaboradores (1975) observaram diferenças significativas com relação a alguns destes componentes, por exemplo, a expressão do afeto e a proporção de alterações da fala, além da latência, em função do gênero do interlocutor. Entretanto, este autor utilizou um conjunto de cenas de asserção positiva e negativa, assim como interlocutores familiares ou não, contrariamente ao presente trabalho que empregou apenas cenas de asserção negativa e interlocutores familiares, o que poderia talvez explicar a diferença nos resultados.

Em resumo, podemos concluir que os pacientes da presente amostra apresentaram maior grau de dificuldade em serem assertivos do que seu grupo de referência na comunidade e que esta dificuldade se referia principalmente, mas não só, aos componentes verbais, se estendendo também aos componentes não-verbais da assertividade.
Além disso, estas dificuldades foram maiores quando se tratava de situações em que o sujeito recebia uma crítica do seu interlocutor, comparativamente às situações de fazer críticas. Os resultados da presente pesquisa mostraram ainda que as dificuldades de assertividade dos pacientes psiquiátricos independem do contexto cultural em que estão inseridos, uma vez que os dados da presente amostra confirmam os obtidos em diferentes culturas.

A habilidade de ser assertivo é necessária em diferentes níveis do funcionamento social na comunidade. Diversas situações sociais cotidianas, tanto dentro quanto fora de casa, requerem um comportamento assertivo das pessoas, em circunstâncias simples tais como as estudadas aqui. O paciente psiquiátrico, em particular, se beneficiaria de programas de treinamento desta habilidade, tendo em vista sua dificuldade de assertividade. Programas de treinamento de habilidades sociais e de assertividade têm sido amplamente utilizados como parte integrante da readaptação social de pacientes psiquiátricos. Por exemplo, o programa desenvolvido por Liberman (Liberman e cols., 1993), considerado uma referência nesta área, inclui em seus diversos módulos de aprendizagem, o treinamento de comportamentos assertivos em situações cotidianas pertinentes para os pacientes psiquiátricos, nas quais eles exercitam a capacidade de resolver situações interpessoais, tais como recusar demandas inconvenientes, expressar necessidades, pedir mudanças de comportamentos, solicitar ajuda. Os resultados obtidos no presente trabalho mostraram a necessidade de se incluir o treinamento da assertividade nos programas de reabilitação psicossocial dos pacientes psiquiátricos implementados em nosso meio, visando capacitar estes pacientes ao enfrentamento de situações sociais conflitantes, que podem resultar em uma melhora de sua qualidade de vida.

O presente trabalho coloca em destaque igualmente a necessidade de se utilizar, nas pesquisas observacionais sobre habilidades sociais e comportamento assertivo, uma metodologia de avaliação do comportamento que envolva a utilização de critérios rigorosos nos procedimentos de coleta de dados, tais como os adotados pelos principais pesquisadores nesta área (Bellack, 1983; Bellack e cols., 1990; Bellack, Turner, Hersen \& Kazdin, 1986; Eisler e cols., 1975; Mueser e cols., 1990). Cabe ressaltar a importância de se seguir estes critérios rigorosos, quando se utiliza dados coletados por observadores, para que se possa obter medidas válidas e confiáveis. Estas medidas requerem a observação independente dos observadores, que deve ser cega aos grupos estudados, procedimentos padronizados de avaliação e definições detalhadas dos comportamentos a serem observados. Destacamos em particular a importância do treinamento cuidadoso dos 
observadores, envolvendo a discussão diária sobre os desacordos obtidos, a explicitação de critérios comuns de avaliação e o feedback contínuo através do cálculo diário da porcentagem de acordo inter-juizes. Além disso, na própria coleta de dados após o treinamento, é importante dar continuidade ao uso do feedback diário para manter o nível elevado do desempenho dos observadores. Pesquisas futuras utilizando esta metodologia poderão identificar outros componentes relevantes no estudo do comportamento assertivo de pacientes psiquiátricos.

\section{Referências}

Bandeira, M., Cardoso, C. S., Fernandes, M. L., Resende, R. A. \& Santos, S C.A S. (1998). Competência social de psicóticos: Validação social habilidades específicas. Jornal Brasileiro de Psiquiatria, 47(5), 217-226. Bandeira, M. \& Tremblay, L. (1998). Competência social de psicóticos Um estudo de validação social. Jornal Brasileiro de Psiquiatria, 47(4), 185192.

Bandeira, M., Pereira, E. A. \& Machado, E. L (1999). Comportamento assertivo de psicóticos: Validação social de dificuldades específicas [Resumo]. Em Sociedade Brasileira de Psicologia (Org.), Resumos de [Resumo]. Em Sociedade Brasileira de Psicologia (Org.), Resumos de
comunicaćés cientificas, XXIX Reunião Anual de Psicologia (p. 63). Campinas: comunic

Bellack, A. S. (1983). Recurrent problems in the behavioral assessment of social skill. Behavior Research and Therapy, 21(1), 29-41.

Bellack, A. S., Morrison, R. L., Mueser, K. T, Wade, J. H. \& Sayer, S. I (1990). Role play for assessing the social competence of psychiatric patients. Journal of Consulting and Clinical Psychology, 2(3), 248-255.

Bellack, A. S., Morrison, R. L \& Mueser, K. T. (1989). Social problem solving in schizophrenia. Schiropbrenia Bulletin, 15(1),101-116.

Bellack, A. S., Turner, S. M., Hersen, M. \& Kazdin, A. S. (Orgs.) (1986). An examination of the efficacy of social skills training for chronic schizophrenic patients. Hospital and Community Psychiatry, 35, 10231028.

Brown, G. T. \& Carmichael, K. (1992). Assertiveness training for clients with a psychiatric illness: A pilot study. British Journal of Occupacional Theratpy, 55(4), 137-141

Caballo, V. E. (1996). Manual de téenicas de terapia e modificacãa do comportamento São Paulo: Santos Livrari

Cyr, M., Hodgins, S., Gaston, L. E. \& Viens, L. (1990). La vie au sein d'appartements surveillés pour patients psychiatriques chroniques. Revne Canadienne de Santé Mentale Communautaire, 9(1), 23-37.

Del Prette, Z. A. P. \& Del Prette, A. (1999). Psicologia das babilidades sociais: Terapia e educacão. Petrópolis: Vozes.
Eisler, R. M., Hersen, M., Miller, P. M. \& Blanchard, E. B. (1975). Situational determinants of assertive behaviors. Journal of Consulting and Clinical Psychology, 43(3), 330-340

Gambrill, E. D. (1978). Behavior Modification: Handbook of assessment, intervention and evaluation. Washington: Jossey-Bass.

Hogarty, G. E., Anderson, C. M., Reiss, D. J., Kornblith, S. J., Greenwald, D. P., Ulrich, R. F. \& Carter, M. (1991). Family psychoeducation, social skills training, and maintenance chemotherapy in the aftercare treatment of schizophrenia. Archives of General Psychiatry, 48, 340-347.

Lange, J. L. \& Jakubowski, P. (1976). Responsible Assertive Behavior. Illinois: Research Press Co

Lazarus, A. A. (1971). Behavior Theratpy and Beyond. New York: McGraw-Hill. Lazarus, A. A. (1971). Beham

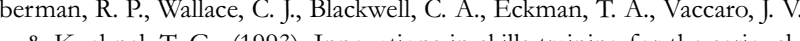
\& Kuehnel, T. G. (1993). Innovations in skills training for the seriously mentally ill: The UCLA social and independent living skills modules. Innovations and Research, 2, 43-60.

Lipp, M. N., Haythornthwaite, J. \& Anderson, D. E. (1996). Medidas diversas da assertividade em adultos. Estudos de Psicologia, 13, 19-26.

Millbrook, J. M. \& Farrell, A D. (1986). Behavioral components of social skills: A look at subject and confederate behaviors. Behavioral Assessment, 8, 203-220.

Morrison, R. L. \& Bellack, A. S. (1987). Social functioning of schizophrenia patients: Clinical and research issues. Schizophrenia Bulletin, 13, 715725.

Mueser, K. T., Bellack, A. S., Morrison, R. L. \& Wade, J. H. (1990). Gender, social competence and symptomatology in schizophrenia: A longitudinal analysis. Journal of Abnormal Psychology, 99(2), 138-147.

Mueser, K. T., Bellack, A. S., Douglas, G. S. \& Morrison, R. L. (1991). Prevalence and stability of social skills deficits in schizophrenia. Schizophrenia Research, 5, 167-176.

Mueser, K. T., Wallace, C. J. \& Liberman, R. P. (1995). New developments in social skills training. Behavior Change, 12(1), 31-40.

Rathus, E. (1975). Principles and practices os assertive training: An ecletic overview. The Counseling Psychologist, 5(4), 9-19.

Tremblay, L. (1992). Évaluation de la competence sociale de personnes souffrant de troubles mentanx graves: Études de validation sociale. (Relatório n. RS-1725089) Montréal, Canada: Conseil Québecois de la Recherche Sociale. (RS-1725-089).

Trower, P. (1980). Situational analysis of the components and processes of behavior of socially skilled and unskilled patients. Journal of Consulting and Chinical Psychology, 48, 327-339.

Wolpe, J. (1969). The practice of behavior theraty. New York: Pergamon Press. Zubin, J. \& Spring, B. (1977). Vulnerability: A new view of schizophrenia. Journal of Abnormal Psychology, 86, 103-126.

Sobre os autores:

Marina Bandeira é Professora do Departamento de Psicologia da Fundação de Ensino Superior de São João del Rei (FUNREI). Doutora em Psicologia pela Université de Montréal, Canada. Pesquisadora do CNPq. Pos-doutorado no Psychosocial Research Center da McGill University. Coordenadora do Laboratório de Pesquisa em Saúde Mental (LAPSAM) da FUNREI.

Elaine Leandro Machado é Psicóloga formada pelo Departamento de Psicologia da FUNREI. Edneia Aparecida Pereira é Psicóloga formada pelo Departamento de Psicologia da FUNREI. 